\title{
Differences in genetic structure between two Japanese beech (Fagus crenata Blume) stands
}

\author{
MAKOTO TAKAHASHI* $\uparrow$, MINORU MUKOUDA $\dagger \&$ KOOZOO KOONO \\ $\dagger$ Tohoku Regional Breeding Office, Forest Tree Breeding Centre, Takizawa, Iwate 020-0173, Japan and $\$$ Hokkaido \\ Regional Breeding Office, Forest Tree Breeding Centre, Ebetsu, Hokkaido 069-0836, Japan
}

\begin{abstract}
To examine the effects of forest cutting on within-population genetic structure, the genetic structure and variability of two Japanese beech (Fagus crenata Blume) stands with contrasting histories in relation to cutting were investigated. Six hundred and sixty beech trees, covering two hectares in total, were mapped and genetically analysed using nine isozyme loci encoding eight enzyme systems. The proportion of polymorphic loci, the average number of alleles per locus, the effective number of alleles per locus, the expected heterozygosity and the observed heterozygosity were 78, 3.3, 1.31, 0.200 and 0.189 , respectively, in a secondary stand (designated AK) cut during the 1920s. Corresponding figures were $78,3.3,1.33,0.203$ and 0.193 , respectively, in a primary stand designated KU. The inbreeding coefficient and the grand mean of the number of alleles in common (NAC) were 0.055 and 1.684 in $\mathrm{AK}$, and 0.042 and 1.649 in KU, respectively. The genetic variability was slightly but significantly lower in AK. The genetic structure of the two stands was strikingly different. The proportions of positively significant Moran's $I$ and SND values found in the shortest distance class were 0.86 and 0.38 for $\mathrm{AK}$, and 0.14 and 0.29 for KU, respectively. Furthermore, significant linkage disequilibrium was observed in AK, but none at all in KU. To examine which, if any, differences in the genetic structure would be likely to influence succeeding generations, we simulated a self-thinning process. The simulation suggested that reduced genetic variability and linkage disequilibrium would have significant influence in the AK stand for several generations.
\end{abstract}

Keywords: Fagus crenata, founder effect, isozyme variability, linkage disequilibrium, self-thinning, spatial autocorrelation.

\section{Introduction}

Forest tree species are genetically more diverse than most other life forms. Generally, the autosomal genetic variation of such species is largely found in the withinpopulation component, and factors such as range of geographical distribution, mating system and seed dispersal all influence the genetic variability retained in the species (Hamrick et al., 1992). As a tool to study how genetic variation is distributed within populations, spatial autocorrelation techniques (Sokal \& Oden, 1978a,b) have played an important role in many studies of genetic structure in forest tree species. These techniques are effective for identifying the major genetic processes involved in the generation of genetic structures in specific populations (Sokal \& Jacquez, 1991; Sokal et al., 1997). Simulation studies and forest tree popula-

*Correspondence. E-mail: makotot@affrc.go.jp

(C) 2000 The Genetical Society of Great Britain. tion studies have revealed that mating system and seed dispersal have considerable influence on within-population genetic structure (Sokal \& Wartenberg, 1983). Coniferous species (in which pollination and seed dispersal occurs mainly by wind, and outcrossing rates are high) have often shown random or only weakly autocorrelated distributions of genotypes (Epperson \& Allard, 1989; Knowles, 1991; Xie \& Knowles, 1991). In contrast, populations of species in which seed dispersal is limited have often shown genetic clustering. Quercus species, in which seeds are dispersed by gravity, are typical. For example, in a continuous old-growth stand of $Q$. laevis studied by Berg \& Hamrick (1995), the population showed one of the highest proportions recorded of positively significant autocorrelation, over scales of $10 \mathrm{~m}$ or less, presumably because of limited seed dispersal. However, the degree of autocorrelation observed was not as strong as that predicted by the authors' simulations. The authors suggested that pollen 
flow and bird-cached seed may have had important effects on the genetic structure of the stand, which was less pronounced than expected given the isolation by distance.

Anthropological disturbances such as forest cutting and fragmentation also influence genetic structure. Knowles et al. (1992) studied two anthropologically disturbed Larix laricina populations: one regenerated from a site with scattered remnant trees, but not surrounded by an off-site seed source, and the other regenerated from a site lacking remnant trees but surrounded by an abundant off-site seed source. The former showed autocorrelation whereas the latter did not. Two out of six correlograms in the former population were significant according to the Bonferroni criterion. The cited authors considered that the limited number of remnant trees may have acted as point seed sources, so the progenies were less mixed in this stand. Young \& Merriam (1994) studied four fragmented and four continuous Acer saccharum populations, and found effects of fragmentation on the spatial genetic structure. Positive autocorrelations, suggesting a reduced degree of mixing of progenies, were found in the shortest distance class in fragmented populations, and negative autocorrelations were observed in the longest distance class, suggesting that incorporation of immigrant pollen pools occurred in mating events at forest patch edges.

Fagus crenata Blume is common in cool temperate broad-leaved deciduous forests in Japan, especially in the mountainous areas alongside the Japan Sea, where heavy snowfall occurs. Fagus crenata is also genetically diverse and almost all of the autosomal genetic variation of the species is maintained in the withinpopulation component $\left(G_{\mathrm{ST}}=0.038\right.$; Tomaru et al., 1997). Understanding the genetic processes operating in natural populations is one of the most important goals in population and conservation genetics, because such knowledge is essential for enhancing the quality of conservation, for management of genetic resources, and for controlling the potential risk of genetic deterioration. We therefore studied the genetic structure and variability of two Fagus crenata (Japanese beech) stands that have had strongly contrasting histories in terms of cutting, using spatial autocorrelation and other relevant statistics, to clarify the influence of forest cutting on the genetic structure of the stands. The following questions were addressed in this study. Does forest cutting influence the genetic structure in the two stands? If so, how do the genetic structures differ between the two stands, and what differences in the genetic structure are likely to influence succeeding generations?

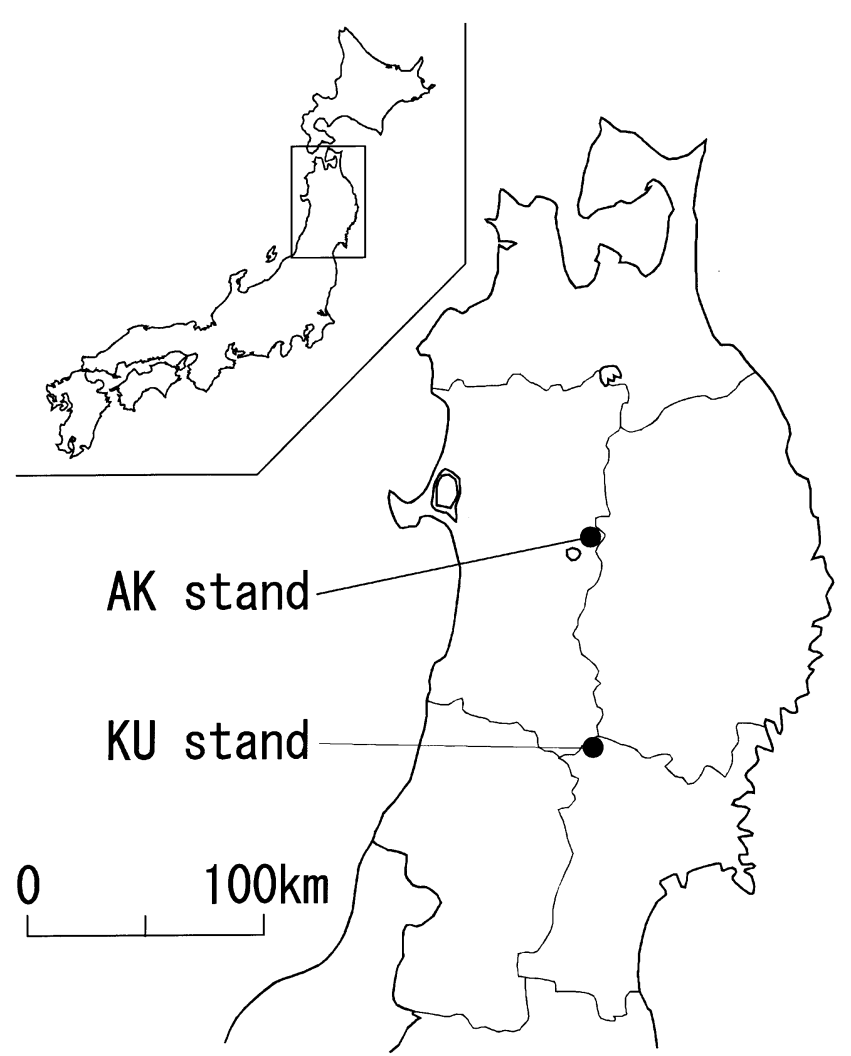

Fig. 1 Locations of the two studied Fagus crenata stands.

\section{Materials and methods}

\section{Studied stands, sampling and isozyme analysis}

Two stands of Fagus crenata forest were studied. One is located at the northern foot of Mt. Akitakomagatake $\left(840 \mathrm{~m} ; 39^{\circ} 47^{\prime} 30^{\prime \prime} \mathrm{N}, 140^{\circ} 48^{\prime} 0^{\prime \prime} \mathrm{E}\right.$; designated $\left.\mathrm{AK}\right)$ in Akita Prefecture, and the other is located at the southern foot of Mt. Kurikoma ( $870 \mathrm{~m} ; 38^{\circ} 55^{\prime} 30^{\prime \prime} \mathrm{N}$, $140^{\circ} 47^{\prime} 50^{\prime \prime} \mathrm{E}$; designated KU) in Miyagi Prefecture in northern Honshu, Japan (Fig. 1). Both stands are located in the Ohu Mountains, where F. crenata forest is predominant. $\mathrm{KU}$ is located $\approx 90 \mathrm{~km}$ south of $\mathrm{AK}$.

A 0.77-ha survey plot was delineated in AK, and all 486 trees taller than $3 \mathrm{~m}$ in the plot were mapped, and a 1.23-ha survey plot was delineated in KU, in which 174 trees taller than $5 \mathrm{~m}$ were mapped. The height and diameter at breast height (d.b.h.) of the 660 mapped trees were then measured, and histograms of d.b.h. distribution are shown in Fig. 2. The ranges of height and d.b.h. were 3-27 $\mathrm{m}$ and 2-92 $\mathrm{cm}$ in AK, and 8-25 $\mathrm{m}$ and $13-109 \mathrm{~cm}$ in $\mathrm{KU}$, respectively. The means and standard deviations of the height and d.b.h. values were $16.0 \pm 5.0 \mathrm{~m}$ and $18.3 \pm 11.4 \mathrm{~cm}$ in $\mathrm{AK}$, and $19.6 \pm 3.0 \mathrm{~m}$ and $46.7 \pm 18.2 \mathrm{~cm}$ in $\mathrm{KU}$, respectively. 
Fig. 2 Distributions of diameter at breast height (d.b.h.) in (a) the AK stand and (b) the KU stand of Fagus crenata.

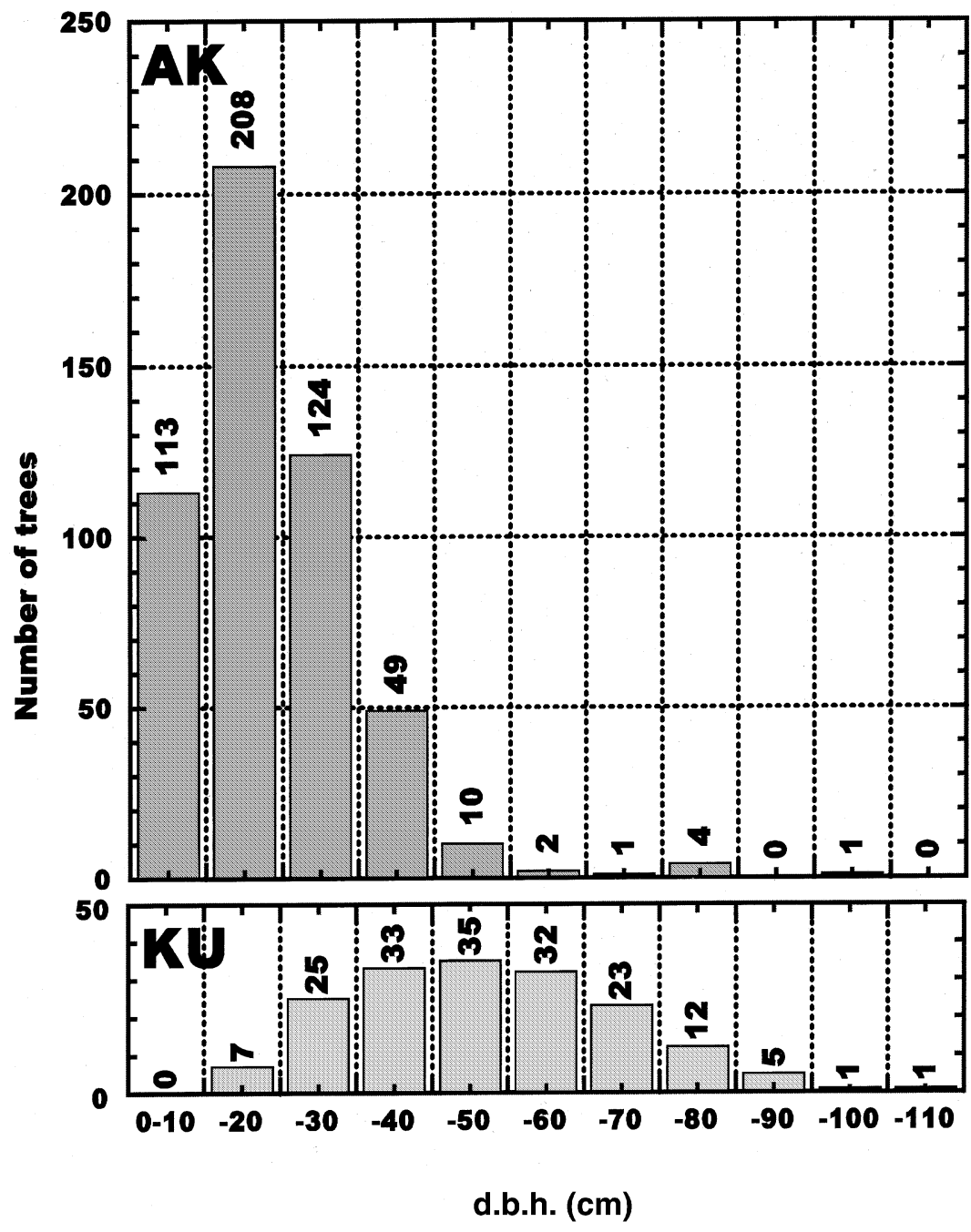

The tree density and basal area of $F$. crenata were 665.0 trees ha $\mathrm{ha}^{-1}$ and $23.9 \mathrm{~m}^{2} \mathrm{ha}^{-1}$ in AK, and 141.5 trees ha and $27.8 \mathrm{~m}^{2} \mathrm{ha}^{-1}$ in $\mathrm{KU}$, respectively.

The two stands have contrasting histories in relation to forest cutting. $\mathrm{KU}$ is thought to be primary beech forest, but AK was cut during the 1920s. A few beech trees were left as mother trees at that time. The remnant trees in the AK stand could be easily recognized because they had much larger diameters (greater than $70 \mathrm{~cm}$ ) than newly regenerated trees.

Experimental samples (winter buds) were collected from all mapped trees, and the following nine loci, encoding eight enzyme systems, were analysed: $M d h-3$ (EC 1.1.1.37), 6 Pg-2 (EC 1.1.1.44), Dia-1 and Dia-2 (EC 1.8.1.4), Got (EC 2.6.1.1), Amy-3 (EC 3.2.1.1), Aap-1 (EC 3.4.11.2), Fm (EC 4.2.1.2) and Pgi-1 (EC 5.3.1.9). The details of the procedures for isozyme analysis have been described previously (Tsumura et al., 1990; Tomaru et al., 1997).

\section{Data analysis}

The proportion of polymorphic loci ( $P l$; we regarded the loci where frequency of the most frequent allele is less than 0.95 as polymorphic loci), the average number of alleles per locus $(\mathrm{Na})$, the effective number of alleles per locus ( $N e$; Kimura \& Crow, 1964), the observed heterozygosity $\left(H_{\mathrm{o}}\right)$ and the expected heterozygosity $\left(H_{\mathrm{e}}\right)$ were calculated to determine the degree of genetic variability within the two stands. The $H_{\mathrm{e}}$ values were derived by averaging $h_{\mathrm{e}}$ over nine loci, where $h_{\mathrm{e}}=2 n\left(1-\Sigma p_{i}^{2}\right) /(2 n-1), p_{i}$ is the allele frequency of the $i$ th allele at a given locus, and $n=$ sample size (Nei, 1987).

We also calculated two types of coefficients of spatial autocorrelation: SND for nominal data and Moran's $I$ for interval data. In the nominal case, the number of joins of every genotype combination was counted at a given locus in a given distance class. The nominal 
autocorrelation test statistic is the standard normal deviate (SND) of the observed number of joins from the expected number of joins (Sokal \& Oden, 1978a): $\mathrm{SND}=($ Observed joins - Expected joins $) /$ Variance ${ }^{1 / 2}$. The SNDs are assumed to be normally distributed, and therefore they have critical values of \pm 1.96 at the $5 \%$ level of significance. Genotypes whose frequencies lie outside the range $0.05-0.95$, and whose expected numbers of joins are less than unity, are excluded from calculation of the SND. Joins between individuals having identical genotypes are referred to as like joins, and joins between individuals having different genotypes are referred to as unlike joins. Sixteen like joins and 11 unlike joins in $\mathrm{AK}$ and 14 like joins and 11 unlike joins in $\mathrm{KU}$ satisfied our criteria, and were used for the calculation.

In the interval case, genotypes of each individual were transformed to $0.0,0.5$ or 1.0 according to the number of the copies of a given allele they possessed. Then Moran's $I$ coefficients were calculated using the following formula (Sokal \& Oden, 1978a): $I=n \Sigma \Sigma \mathbf{w}_{i j} \mathbf{z}_{i} \mathbf{z}_{j} /$ $\left(W \Sigma \mathbf{z}_{i}^{2}\right)$, where $n=$ sample number; $\mathbf{w}_{i j}=$ join matrix, being set to unity if the $i$ th and $j$ th individuals are in the distance class, and zero otherwise, $W=$ the sum of join matrices $\mathbf{w}_{i j} ; \mathbf{z}_{i}=\mathbf{x}_{i}-x$, and $\mathbf{z}_{j}=\mathbf{x}_{j}-x$. The variables $\mathbf{x}_{i}$ and $\mathbf{x}_{j}$ are the genotypic scores for the $i$ th and $j$ th individuals, respectively, and $x$ is the mean score for all trees of the studied stand. The expected value of $I=-1 /(n-1)$. The variance of $I$ was calculated following the formulae of Sokal \& Oden (1978a), and significance levels were calculated from SNDs on the assumption that $I$ is normally distributed. We divided the AK plot into 19 subplots of $20 \mathrm{~m} \times 20 \mathrm{~m}$ and the KU plot into 18 subplots of $30 \mathrm{~m} \times 30 \mathrm{~m}$, and calculated allele frequencies in all the subplots and Pearson's correlation coefficients among them. If a pair of alleles in a certain locus was significantly negatively correlated, one allele was excluded from the following analyses to avoid nonrandom sampling of alleles, because it is well established that similar gene frequency surfaces yield similar correlograms (Sokal \& Oden, 1978b; Sokal \& Wartenberg, 1983). Furthermore, alleles with frequencies lying outside the range $0.05-0.95$ are also excluded. The following seven alleles satisfied the two criteria for inclusion in each of the two stands: $M d h-3^{b}, D i a-1^{b}$, Dia- $2^{b}$, Amy $-3^{b}$, Aap $-1^{b}, \mathrm{Fm}^{b}$ and Pgi-1 ${ }^{c}$.

The SND and $I$-values were calculated using three sets of distance class in the two stands: 12 distance classes of $5 \mathrm{~m}$ intervals $(0-5 \mathrm{~m}, 5-10 \mathrm{~m}$ and so on), six distance classes of $10 \mathrm{~m}$ intervals $(0-10 \mathrm{~m}, 10-20 \mathrm{~m}$ and so on), and 20 distance classes, adjusted such that the values of $W$ were practically equal in each class, and so that there was statistically equivalent test power in each class. As analyses using these three types of distance classes showed very similar trends, we consider here only the results from the first type of distance class. The overall significance of the individual correlogram for each allele was assessed using the Šidák procedure (Šidák, 1967). In this procedure, a modified Bonferroni probability level, $\alpha^{\prime}$ for individual tests is calculated from $1-(1-\alpha)^{1 / l}$ where $\alpha$ is set as the Type I error rate (here $\alpha=0.05$ ) and $l$ is taken as the number of distance classes (here $l=12$ ). The average correlograms, which are simply the arithmetic means of the individual correlograms, are calculated for the $I$ and SND values. Their variances are calculated using the bootstrap procedure.

The NAC was calculated over 12 distance classes (i.e. the first type of distance class). The NAC value is the average number of alleles in common per polymorphic locus between pairs of individuals in a given distance class. A mean is calculated for each distance class by averaging the pairwise NAC values following the counting rules of Surles et al. (1990). A grand mean is also calculated by averaging all possible pairwise NAC values without respect to distance. The grand mean represents the null hypothesis of spatial randomness of alleles. To assess the significance of excesses and deficits of NAC, we calculated variances of NAC values in each distance class using the bootstrap procedure. An excess of NAC at a certain distance suggests that individuals in that distance class share more alleles than would be expected in a random distribution. This excess must be offset by a deficit of NAC in other distance classes. The variance of grand mean NAC is also calculated, to examine whether the grand mean NAC values in the two stands differ significantly. The NAC can vary from 0 to 2 , but it usually ranges from 1.25 to 1.75 in natural populations (Hamrick et al., 1993).

The inbreeding coefficient $\left(F_{\mathrm{IS}}\right)$ was derived from averaging $f_{\text {is }}$ over polymorphic loci, where $f_{\text {is }}=1-h_{\mathrm{o}} /$ $h_{\mathrm{e}}, h_{\mathrm{e}}$ is expected heterozygosity, and $h_{\mathrm{o}}$ is observed heterozygosity. Heterogeneity in genotype frequencies at each of the nine loci and linkage disequilibrium between all pairs of nine loci in the two stands were examined using the chi-squared test of the GDA version 1.0 program (Lewis \& Zaykin, 1999). Alleles with frequencies less than 0.05 were pooled together as one allele before the calculation. Some linkage-disequilibriumretained locus pairs were observed in the AK stand, but none was detected in KU. The distribution of twolocus genotypes of linkage-disequilibrium-retained locus pairs was examined by calculating the SND values of two-locus genotypes.

To assess whether the detected linkage disequilibrium is likely to diminish or not as tree density in $\mathrm{AK}$ decreases in the present generation, a simulation of the self-thinning process was carried out, using the d.b.h. data collected for 486 trees in the stand. The ECO-GENE 
(v.1.0) program (Degen et al., 1996) was used for this simulation. In the simulation, the vitality of each tree decreases according to the degree its canopy overlaps with surrounding tree canopies every year. When the vitality of a tree falls to zero, the tree is regarded as dead. We used growth data of Fagus sylvatica provided by the software, and extended the simulation time to 35 years in five-year intervals. Because it is not certain that five-years growth of $F$. sylvatica is equivalent to five-years growth of $F$. crenata, we referred to the fiveyear growth period as a unit of simulation period (thus

Table 1 Detected alleles and their frequencies in the AK and KU stands of Fagus crenata

\begin{tabular}{|c|c|c|c|}
\hline \multirow[b]{2}{*}{ Locus } & \multirow[b]{2}{*}{ Allele } & \multicolumn{2}{|c|}{ Stand } \\
\hline & & AK & $\mathrm{KU}$ \\
\hline \multirow[t]{3}{*}{$M d h-3$} & $a$ & 0.003 & - \\
\hline & $b$ & 0.801 & 0.873 \\
\hline & $c$ & 0.195 & 0.127 \\
\hline \multirow[t]{2}{*}{$6 \mathrm{Pg}-2$} & $c$ & 0.998 & 0.997 \\
\hline & $d$ & 0.002 & 0.003 \\
\hline \multirow[t]{4}{*}{ Dia-1 } & $a$ & 0.032 & 0.069 \\
\hline & $b$ & 0.947 & 0.925 \\
\hline & $c$ & 0.001 & 0.006 \\
\hline & $d$ & 0.020 & - \\
\hline \multirow[t]{4}{*}{ Dia-2 } & $a$ & 0.020 & 0.012 \\
\hline & $b$ & 0.895 & 0.910 \\
\hline & $c$ & 0.085 & 0.071 \\
\hline & $d$ & - & 0.006 \\
\hline \multirow{5}{*}{ Got } & $a$ & 0.005 & - \\
\hline & $b$ & 0.004 & 0.003 \\
\hline & $c$ & 0.982 & 0.975 \\
\hline & $d$ & 0.009 & 0.009 \\
\hline & $e$ & - & 0.012 \\
\hline \multirow[t]{7}{*}{ Amy-3 } & $a$ & 0.013 & 0.032 \\
\hline & $b$ & 0.354 & 0.365 \\
\hline & $c$ & 0.013 & 0.010 \\
\hline & $d$ & 0.005 & 0.016 \\
\hline & $e$ & 0.612 & 0.558 \\
\hline & $f$ & 0.002 & 0.013 \\
\hline & $g$ & - & 0.006 \\
\hline \multirow{3}{*}{ Aap-1 } & $a$ & 0.002 & 0.016 \\
\hline & $b$ & 0.944 & 0.913 \\
\hline & $c$ & 0.053 & 0.072 \\
\hline \multirow[t]{2}{*}{$\mathrm{Fm}$} & $a$ & 0.277 & 0.267 \\
\hline & $b$ & 0.723 & 0.733 \\
\hline \multirow[t]{3}{*}{ Pgi-1 } & $b$ & 0.006 & 0.012 \\
\hline & $c$ & 0.928 & 0.932 \\
\hline & $d$ & 0.066 & 0.056 \\
\hline \multicolumn{2}{|c|}{ Total no. of detected alleles } & 30 & \\
\hline
\end{tabular}

35 simulated years are referred to as the $7 \times$ simulation period). No mating was included in the simulation; we simply examined the process of self-thinning. As the results were identical among five repetitions, we attempted no more repetitions and regarded the results as one repetition. We then calculated two-locus genotypic SND of linkage-disequilibrium-retained locus pairs, standard SND, Moran's I, and linkage disequilibrium values for trees surviving in the simulation.

\section{Results}

\section{Genetic variability}

In total, 33 alleles were detected among nine loci encoding eight enzyme systems in the two stands (Table 1), six of which were present in only one stand. Parameters for evaluating genetic variability are presented in Table 2. The $N e, H_{\mathrm{e}}$, and $H_{\mathrm{o}}$ values in the AK stand are slightly lower than those in KU, although the differences are not significant. The combined average values and standard errors of $\mathrm{Pl}, \mathrm{Na}, \mathrm{Ne}, \mathrm{H}_{\mathrm{e}}$ and $\mathrm{H}_{\mathrm{o}}$ in the two stands were $78.0,3.30 \pm 0.47,1.30 \pm 0.12$, $0.202 \pm 0.057$ and $0.191 \pm 0.053$, respectively.

\section{Spatial autocorrelation}

The following seven alleles satisfied our criteria for selecting alleles and were used for calculating Moran's I-values: $M d h-3^{b}, D i a-I^{b}, D i a-2^{b}, A m y-3^{b}, A a p-1^{b}, F m^{b}$ and $P g i-I^{c}$. As for the nominal case, 16 like joins and 11 unlike joins in $\mathrm{AK}$ and 14 like joins and 11 unlike joins in KU satisfied our criteria and were used for calculating SND. As analyses of the three types of distance classes showed the same trends, only the results from the first type (i.e. 12 distance classes of $5 \mathrm{~m}$ intervals, from 0 to $60 \mathrm{~m})$ are presented.

Table 2 Parameters of genetic variability and inbreeding coefficients in the AK and KU stands of Fagus crenata

\begin{tabular}{lllc}
\hline & \multicolumn{2}{c}{ Stand } & $\begin{array}{c}\text { Difference } \\
\text { between } \\
\text { two stands }\end{array}$ \\
\cline { 2 - 4 } & \multicolumn{1}{c}{$\mathrm{AK}$} & \multicolumn{1}{c}{$\mathrm{KU}$} & \\
\hline $\mathrm{Pl}$ & 78 & 78 & $\mathrm{NS}$ \\
$\mathrm{Na}$ & $3.3(0.4)$ & $3.3(0.5)$ & $\mathrm{NS}$ \\
$\mathrm{Ne}$ & $1.31(0.11)$ & $1.33(0.13)$ & $\mathrm{NS}$ \\
$\mathrm{H}_{\mathrm{e}}$ & $0.200(0.057)$ & $0.203(0.057)$ & $\mathrm{NS}$ \\
$H_{\mathrm{o}}$ & $0.189(0.054)$ & $0.193(0.052)$ & $\mathrm{NS}$ \\
$F_{\mathrm{IS}}$ & $0.055(0.067)$ & $0.042(0.080)$ & $\mathrm{N}$
\end{tabular}

Averages with standard errors in parentheses are shown. $\mathrm{Pl}, \mathrm{Na}, \mathrm{Ne}, \mathrm{H}_{e}, H_{o}$, and $F_{\mathrm{IS}}$ denote proportion of polymorphic loci ( 0.95 criterion), number of alleles per locus, effective number of alleles per locus, expected heterozygosity, observed heterozygosity and inbreeding coefficient, respectively. 

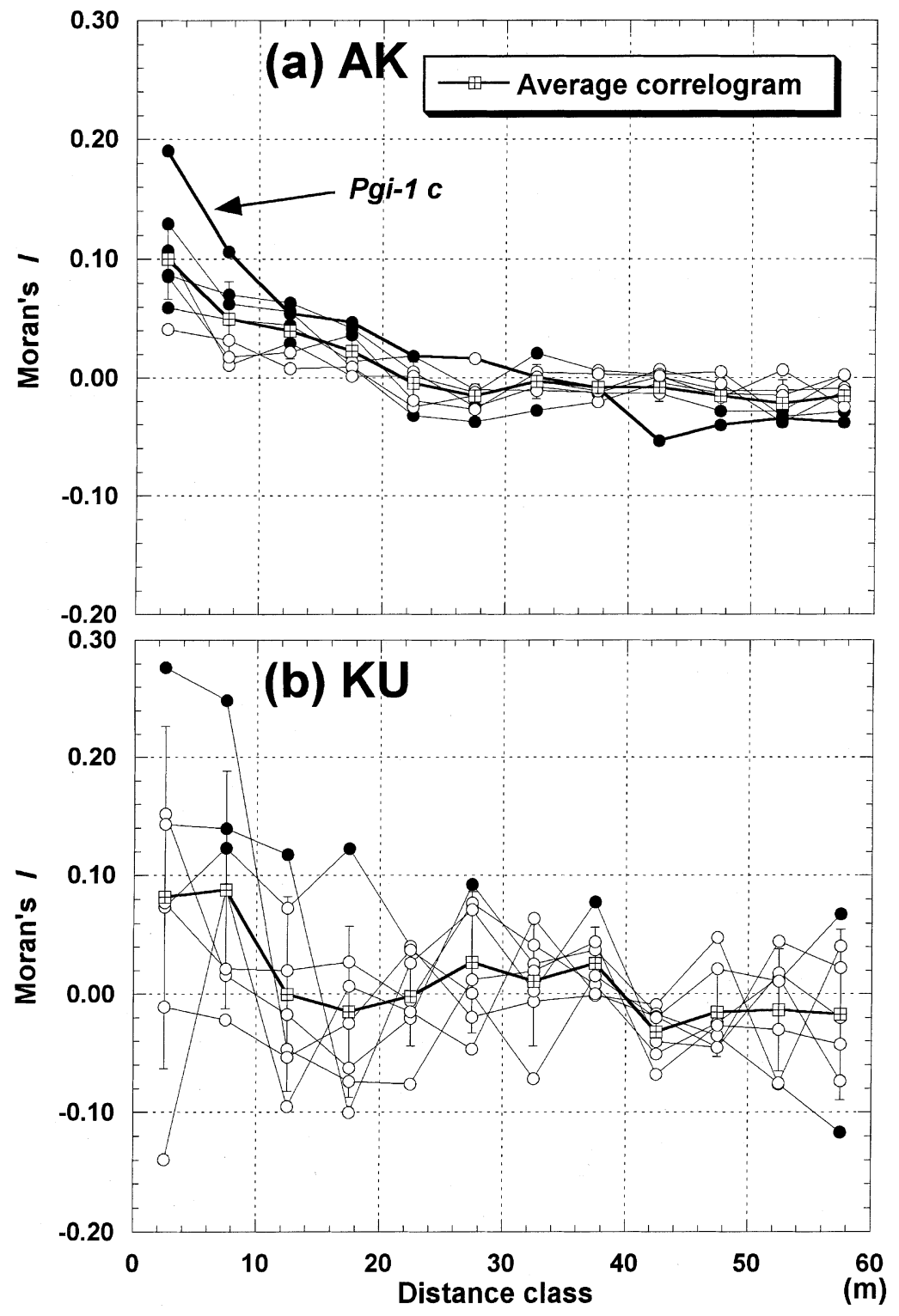

Fig. 3 Individual and average correlograms of Moran's $I$ in the AK and KU stands of Fagus crenata. Variances of the Moran's I-values of the average correlogram were estimated using the bootstrap procedure. Standard deviations of the Moran's I-values of the average correlogram are presented with error bars. Solid circles denote significant Moran's $I$-values at the 5\% probability level. The average correlogram, and correlograms in which Moran's $I$ significantly differed from the $I$-value of the average correlogram in the same distance class at the $5 \%$ probability level are marked with bold lines.
Seven individual allelic correlograms (of Moran's $I$-values) calculated for the two stands are shown in Fig. 3. Six out of seven allelic correlograms $(86 \%)$ in AK showed positively significant $I \mathrm{~s}$ in the shortest distance class (Fig. 4a), and one out of seven correlograms $(14 \%)$ in $\mathrm{KU}$ showed positively significant $I \mathrm{~s}$ in the first distance class (Fig. 4b). Even when the first two distance classes were pooled, the proportion of positively significant $I$ s in KU was only $43 \%$. The proportions of positively significant Is decreased as distance increased in both stands. Significantly negative Is were frequently observed in larger distance classes of AK. Six out of seven allelic correlograms (all but Amy3) in AK, and two out of seven in KU were significant at the $5 \%$ Bonferroni criterion probability level. The average correlograms of the two stands and the variances for the two stands are also shown in Fig. 3. Among 14 individual correlograms, only the $I$-value of the Pgi-I $I^{c}$ allele in the first distance class significantly differed from the average $I$-value $(P<0.05)$.

The proportion of positively significant like joins in the first distance class was 0.38 in $\mathrm{AK}$ and 0.29 in $\mathrm{KU}$ (Fig. 4c,d). The proportion of positively significant like joins in $\mathrm{KU}$ decreased to zero by the fourth distance class, whereas that of AK only did so in the seventh distance class. Negatively significant unlike joins were thought of as the cumulative effect of positive associations of like joins. The proportion of negatively significant unlike joins in the first distance class was 0.27 in 
Fig. 4 (a) and (b) the proportions of significant Moran's I in AK and KU stands, respectively, of Fagus crenata. (c) and (d) the proportions of positively significant SNDs of like joins (PLJ) and negatively significant SNDs of unlike joins (NUJ) in AK and KU, respectively.
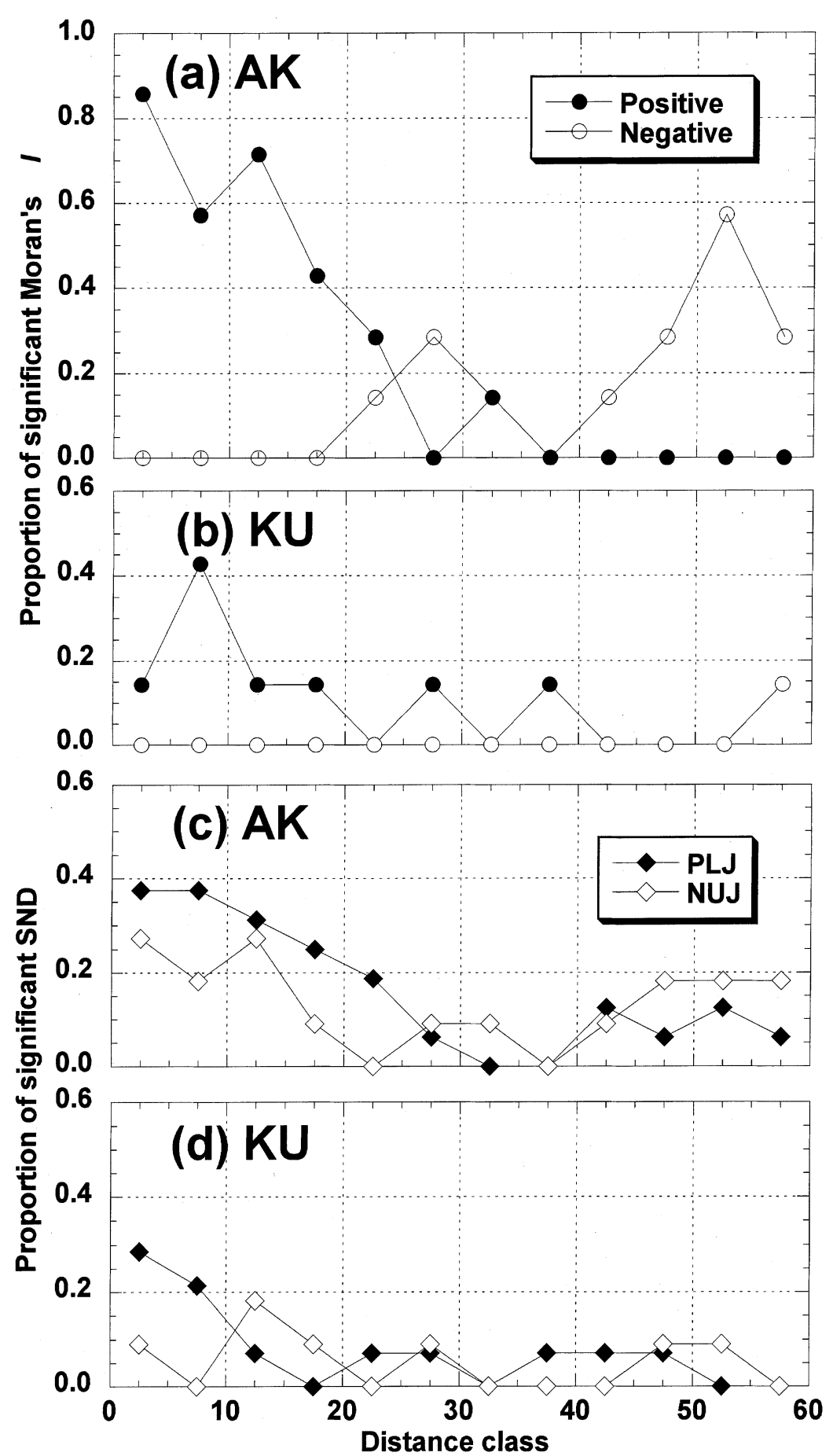

AK and 0.09 in KU. The proportion of negatively significant unlike joins in AK was higher than that of $\mathrm{KU}$ over the first three distance classes.

\section{Number of alleles in common}

The grand mean and the standard deviation of the NAC was $1.684 \pm 0.001$ in $\mathrm{AK}$ and $1.649 \pm 0.002$ in $\mathrm{KU}$, and they differed significantly $(P<0.001)$. The NAC values of the two stands are shown in Fig. 5. The NACs were positively significant in the first three distance classes and negatively significant in the fifth and sixth distance classes in AK, showing the pattern expected according to isolation by distance. The NACs of KU were not significant, except in the second and eighth distance classes.

(C) The Genetical Society of Great Britain, Heredity, 84, 103-115. 


\section{Inbreeding coefficients and linkage disequilibrium}

The $F_{\text {IS }}$ value of AK $(0.055 \pm 0.067)$ was slightly higher than that of $\mathrm{KU}(0.042 \pm 0.080$; Table 2$)$, although the difference was not significant. No heterogeneity in genotype frequencies and no linkage disequilibrium was observed in KU, but both phenomena were detected in AK. The heterogeneity in genotype frequencies at the nine loci, and linkage disequilibria between the pairs of loci for the AK stand, are shown in Table 3. Genotype frequencies at the Aap- 1 locus were significantly heterogeneous $(P<0.001)$. The $f_{\text {is }}$ value at this locus was 0.209 , indicating more homozygotes than expected

Table 3 Chi-squared heterogeneity test for the nine loci and linkage disequilibria among them in the AK stand of Fagus crenata

\begin{tabular}{|c|c|c|c|c|c|c|c|c|c|c|}
\hline & \multicolumn{2}{|c|}{ Heterogeneity } & \multicolumn{8}{|c|}{ Linkage disequilibrium } \\
\hline No. Locus & test & 1 & 2 & 3 & 4 & 5 & 6 & 7 & 8 & 9 \\
\hline$M d h-3$ & & & - & - & - & - & $*$ & $*$ & - & - \\
\hline $6 P g-2$ & & & & - & - & - & - & $*$ & - & - \\
\hline Dia-1 & & & & & - & - & $*$ & $*$ & - & - \\
\hline Dia-2 & & & & & & $*$ & - & $*$ & - & - \\
\hline Got & & & & & & & - & $*$ & $*$ & 一 \\
\hline Amy-3 & & & & & & & & $*$ & - & - \\
\hline Aap-1 & $* * *$ & & & & & & & & $*$ & $*$ \\
\hline$F m$ & & & & & & & & & & - \\
\hline Pgi-1 & & & & & & & & & & \\
\hline
\end{tabular}

under Hardy-Weinberg equilibrium. Combined genotype frequencies between Aap- 1 and the other eight loci also deviated from Hardy-Weinberg equilibrium, at least at the 5\% probability level. Even if the Aap-1 locus was excluded from consideration, linkage disequilibrium still existed for four pairs of loci: $M d h-3-A m y-3$, Dia-1-Amy-3, Dia-2-Got, and Got-Fm.

\section{Simulation of the self-thinning process and its effect on genetic structure}

The two-locus genotype distributions of four linkagedisequilibrium-retained locus pairs were examined by calculating SND values. Four out of 13 like joins genotypic correlograms $(0.31)$ at four linkage-disequilibrium-retained locus pairs showed positively significant SNDs in the first distance class (Table 4). As the present tree density in the AK stand is high (631.2 trees $\mathrm{ha}^{-1}$ ), the observed linkage disequilibrium and the clustering of two-locus genotypes might be diminished during the process of self-thinning. Therefore, we attempted to simulate self-thinning, and to describe the genetic structure of the resultant population using the NAC, the parameters of spatial autocorrelation and linkage disequilibrium (Table 4). The heterogeneity of genotype frequencies at the Aap-1 locus remained nonsignificant until the $3 \times$ simulation period (data not shown). The positively significant SNDs of like joins at the four linkage-disequilibrium-retained locus pairs diminished during self-thinning (falling to zero by the $4 \times$ simulation period), as expected. The proportion of significant $I$ s and standard SNDs in the first distance

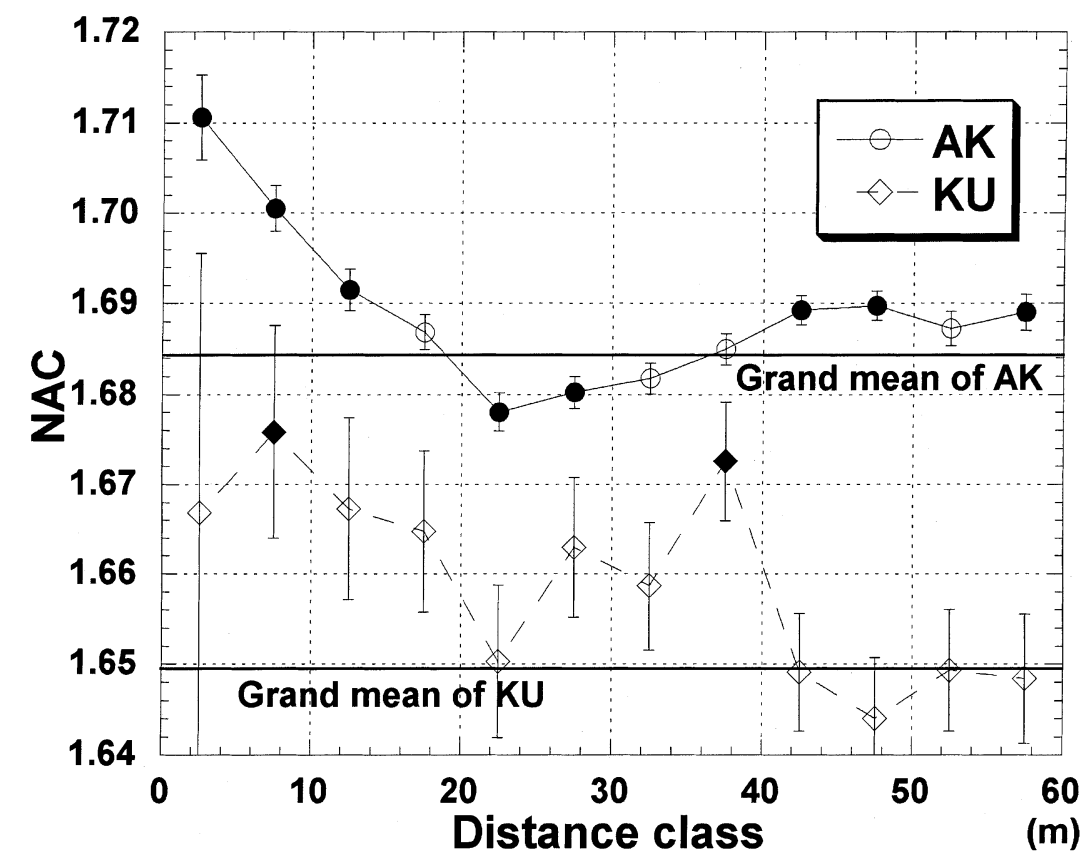

Fig. 5 NAC values over 12 distance classes in the AK and KU stands of Fagus crenata. Grand means of NAC values in the $\mathrm{AK}$ and $\mathrm{KU}$ stands are shown by solid lines. Solid markers denote NAC values which significantly differed from the grand mean NAC value at the $5 \%$ probability level. Variances of the NAC values were estimated using the bootstrap procedure. Error bars show one standard deviation of the NAC values.

(C) The Genetical Society of Great Britain, Heredity, 84, 103-115. 
Table 4 Changes in degrees of linkage disequilibrium and proportions of positively significant SNDs of like joins in the first distance class during the self-thinning simulation using data from the AK stand of Fagus crenata

\begin{tabular}{|c|c|c|c|c|c|c|c|c|}
\hline Simulated period & Present & $1 \times$ & $2 \times$ & $3 \times$ & $4 \times$ & $5 \times$ & $6 \times$ & $7 \times$ \\
\hline Density of surviving trees $\left(\mathrm{ha}^{-1}\right)$ & 631.2 & 513.0 & 402.6 & 319.5 & 245.5 & 203.9 & 172.7 & 141.6 \\
\hline \multicolumn{9}{|l|}{ Linkage disequilibrium } \\
\hline$A m y-3 \& M d h-3$ & $*$ & $* * *$ & $* * *$ & $* * *$ & $* * *$ & **** & $* * *$ & *** \\
\hline Amy-3 \& Dia-1 & * & NS & * & * & * & * & * & NS \\
\hline Got \& Dia-2 & * & * & * & * & * & * & $* *$ & ** \\
\hline Got \& Fm & * & * & * & * & $*$ & * & * & $* *$ \\
\hline \multicolumn{9}{|c|}{ Proportion of positively significant SND of like joins in the first distance class } \\
\hline Amy-3 \& Mdh-3 & $2 / 5$ & $2 / 5$ & $1 / 5$ & $1 / 5$ & $0 / 3$ & $0 / 3$ & $0 / 2$ & $0 / 0$ \\
\hline Amy-3 \& Dia-1 & $1 / 3$ & $0 / 3$ & $0 / 3$ & $0 / 3$ & $0 / 2$ & $0 / 2$ & $0 / 2$ & $0 / 0$ \\
\hline Got \& Dia-2 & $1 / 2$ & $1 / 2$ & $0 / 2$ & $0 / 2$ & $0 / 2$ & $0 / 2$ & $0 / 1$ & $0 / 1$ \\
\hline Got \& Fm & $0 / 3$ & $1 / 3$ & $0 / 3$ & $0 / 3$ & $0 / 2$ & $0 / 2$ & $0 / 2$ & $0 / 1$ \\
\hline
\end{tabular}

class also decreased to zero. Although the linkage disequilibrium was diminished at the Amy-3 and Dia-1 locus-pair, the linkage disequilibrium at the other three pairs was reinforced. The grand mean of the NAC values, and the standard deviation after the $7 \times$ simulation period was $1.665 \pm 0.002$. The NAC decreased from 1.684 (before simulation), but the value still significantly differed from the NAC of the KU $(P<0.001)$. The correlogram of NAC after the $7 \times$ simulation period is presented in Fig. 6 . The NAC in the second distance class is significant $(P<0.05)$. If the first two distance classes are pooled, the NAC correlogram suggests the genetic clustering of multilocus genotypes. It is interesting that the decrease of the grand mean resulted from decreases of the NACs in longer distance classes. The NAC in the first distance class increased substantially $(\Delta=0.075)$ compared to changes in other distance classes.

\section{Discussion}

\section{Genetic variability}

The $N e, H_{\mathrm{e}}$ and $H_{\mathrm{o}}$ values of the AK stand were slightly lower than those of $\mathrm{KU}$, and the $F_{\text {IS }}$ value derived for AK was slightly larger than that of KU. The grand mean of NAC was significantly higher for AK than for $\mathrm{KU}$, indicating there was less genetic variability and higher genetic similarity among individuals in AK. The NAC would be expected to be more sensitive to differences in genetic variability than other parameters used in this study, because it is based on pairs of
Fig. 6 NAC values over 12 distance classes of the AK stand of Fagus crenata after the $7 \times$ simulation period. The grand mean NAC value is shown as a solid line. The solid marker denotes a NAC value that differed significantly from the grand mean NAC value at the $5 \%$ probability level. Variances of the NAC values were estimated using the bootstrap procedure. Error bars show one standard deviation of the NAC values.

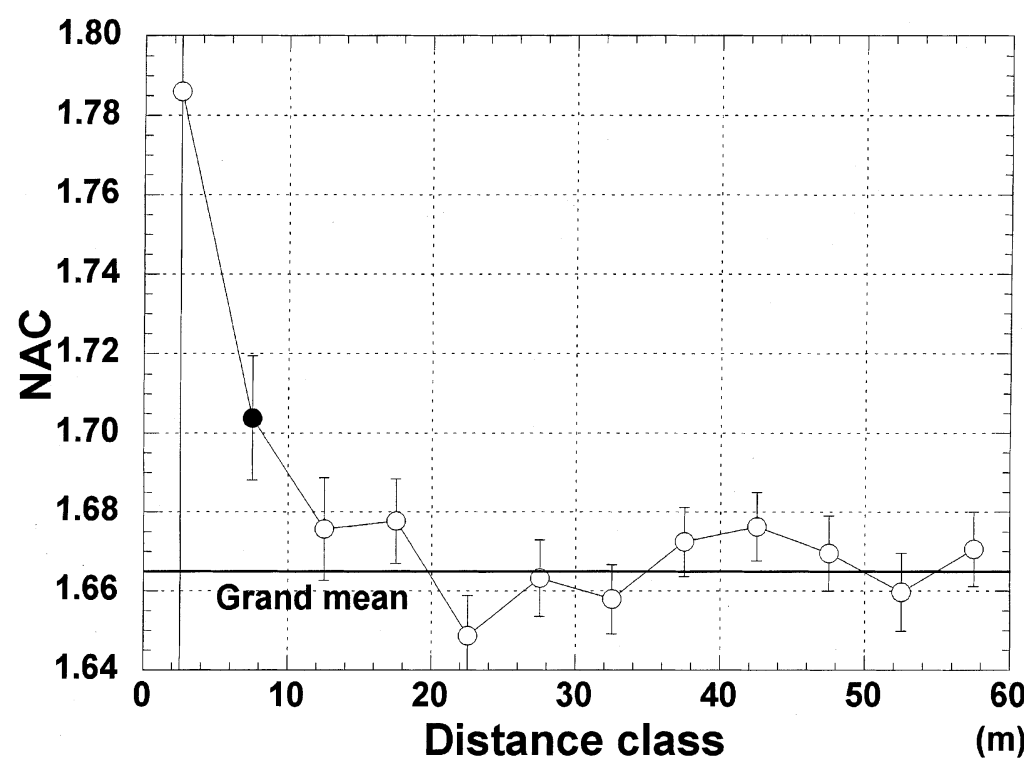


individuals, whereas the other parameters are locusbased. The AK stand was subjected to cutting during the 1920 s, and tree density of the stand was reduced to 6.5 trees $^{-1}$ at that time. The slight, but significantly, lower genetic variability found in $\mathrm{AK}$ is attributable to the founder effect caused by the cutting, which left just a few trees standing. The degree to which the genetic variability was reduced by the cutting would have been weakened by pollen flow from surrounding stands, if present (see below).

\section{Genetic structure}

The proportions of positively significant $I$ and positively significant like joins in short distance classes were higher than in longer distance classes (Fig. 4), indicating the existence of genetic clustering in both stands. However, the degree of the autocorrelation differed markedly between the stands. The proportions of positively significant $I(0.14)$ and SND values of like joins $(0.29)$ in the first distance class in KU are more obvious than the genetic structure found for some conifer species. The proportions of positively significant $I$ s found in previous studies include $8-14 \%$ in two Picea mariana (Knowles, 1991) and 2-9\% in three Pinus banksiana stands (Xie \& Knowles, 1991). The significant SND was $7 \%$ in two Pinus contorta ssp. latifolia (Epperson \& Allard, 1989). However, the genetic structure observed in $\mathrm{KU}$ is still in the range found for other Fagaceae tree species. Proportions of significant $I$ s found in previous studies include $67 \%$ in a Quercus laevis stand (Berg \& Hamrick, 1995), 44\% in a Q. macrocarpa stand (Gebrek \& Knowles, 1994), and $25 \%$ in a $F$. crenata stand (Kawano \& Kitamura, 1997). Previously published SND values range from 10 to $14 \%$ in two French $F$. sylvatica populations (Merzeau et al., 1994) and from 0 to $25 \%$ in 14 Italian F. sylvatica populations (Leonardi \& Menozzi, 1996). Thus, the genetic structure found in KU is fairly high compared to estimations for related species. Limited seed dispersal is presumably related to the observed genetic structure in this stand, as seeds of $F$. crenata are abundantly dispersed up to $10 \mathrm{~m}$ around a mother tree, but usually not dispersed beyond $30 \mathrm{~m}$ (Yanagiya et al., 1969; Maeda, 1988). Kawano \& Kitamura (1997) estimated genetic neighbourhood area $(A)$, which is defined as the area centred on individuals within which $86.5 \%$ of parents are to be detected, to be $A=3050$ $4091 \mathrm{~m}^{2}$, equivalent to a circle of $31.2-36.1 \mathrm{~m}$ radius. Similarly, Troggio et al. (1996) estimated mean pollenflow distance to be $31.7 \mathrm{~m}$ in a $F$. sylvatica stand. Demesure et al. (1996) reported maternally inherited cpDNA to be more highly differentiated $\left(G_{\mathrm{ST}}=0.83\right)$ than nuclear DNA $\left(G_{\mathrm{ST}}=0.054\right)$, according to an isozyme analysis of 85 Fagus sylvatica populations. Tomaru et al. (1998) also found a striking difference between genetic differentiation of maternally inherited mtDNA $\left(G_{\mathrm{ST}}=0.963\right)$ and nuclear-coded isozyme markers $\left(G_{\mathrm{ST}}=0.039\right)$ among $17 F$. crenata populations. These findings indicate that there is a much higher level of pollen flow than seed dispersal. Tomaru et al. (1997) estimated the average number of migrants exchanged per generation $(\mathrm{Nm})$ to be 6.3 , which is significantly higher than the level believed to be necessary to prevent population differentiation $(\mathrm{Nm}>1)$.

The proportion of positively significant $I$ and SND values in $\mathrm{AK}$ ( 0.86 and 0.38 , respectively) are much higher than the corresponding quantities in $\mathrm{KU}$ and in other Fagaceae species. The forest cutting is presumed to be tightly related to the strong genetic structure in AK (see below). Negatively significant Is were frequently observed in longer distance classes in $\mathrm{AK}$ (more than $40 \mathrm{~m}$; Fig. 4a), indicating considerable genetic dissimilarity among trees separated by large distances. This is attributable to the limited number of reproductive trees with different genotypes responsible for establishing the present tree population. Thirteen out of 14 correlograms did not differ from the average correlogram, suggesting that no selection operates over these 13 alleles. Only the $P g i-I^{c}$ correlogram (in the first distance class; $P<0.05$ ) in the AK stand was significantly different from the average correlogram (Fig. 3a). Two remnant trees with a d.b.h. greater than $70 \mathrm{~cm}$ had a $c / d$ genotype at the Pgi-1 locus (Fig. 7), and around the more southerly one there was a cluster of trees sharing this genotype. The clustering is clearly responsible for the particularly high $I$-value in the first distance class at the locus. We did not regard the clustering as evidence of selection.

\section{Differences in genetic structure and variability between stands}

There were contrasting results between the $\mathrm{AK}$ and $\mathrm{KU}$ stands. First, no linkage disequilibrium was observed in KU. The genotype frequency of the Aap- 1 locus in AK, however, deviated from Hardy-Weinberg equilibrium (Table 3), and four locus pairs showed linkage disequilibrium. Secondly, the proportions of positively significant Is (0.86) and positively significant like joins (0.38) in the first distance class in AK were higher than the corresponding proportions in KU (0.14 and 0.29, respectively; Fig. 4). Thirdly, the grand mean of NAC in AK is significantly $(P<0.001)$ higher than that of KU. The founder effect caused by the forest cutting in AK during the 1920s is almost certainly responsible for these differences. 


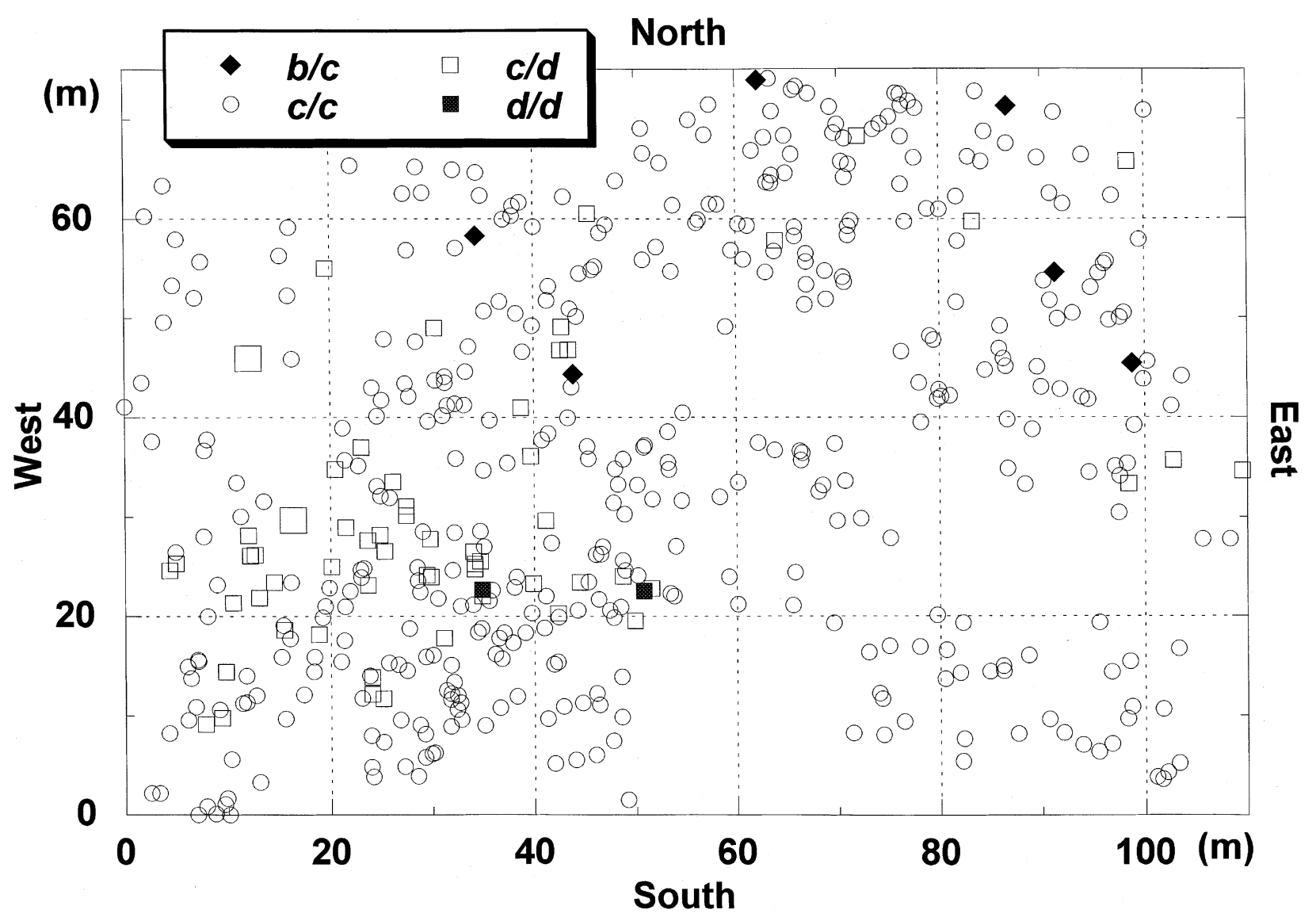

Fig. 7 Scattergram of four genotypes at the Pgi-1 locus in the AK stand of Fagus crenata. The two larger squares show remnant trees (with d.b.h.s greater than $70 \mathrm{~cm}$ ) with the $c / d$ genotype, the southerly one surrounded by a cluster of newly regenerated trees sharing this genotype.

The linkage disequilibria of combined genotype frequencies between the Aap- 1 locus and the other eight loci are attributable to the heterogeneity of genotype frequency at the Aap- 1 locus itself. However, four other two-locus combinations also retained linkage disequilibrium (Table 3). A dramatically reduced density of reproductive trees would be expected to induce genetic drift in the genetic composition of remnant trees (Hartl \& Clark, 1997). A decrease in density of reproductive trees reduces the degree of overlap of seed shadows of different mother trees, and consequently reduces mixing of different progenies, which would increase the level of genetic clustering. Young \& Merriam (1994) studied four fragmented and four continuous Acer saccharum natural populations, and found less mixing of genotypes in fragmented than in continuous populations. Knowles et al. (1992) also reported that populations that regenerated from limited numbers of reproductive trees showed more obvious genetic structure in Larix laricina populations.

\section{Effect of self-thinning on genetic structure and variability}

The present tree density of AK is quite high (631.2 trees $\mathrm{ha}^{-1}$ ). It is important to know whether the observed differences in genetic structure between two stands will be diminished during the self-thinning process. Simulation of the self-thinning process suggested that the genetic clustering of two-locus genotypes of four linkage-disequilibrium-retained locus pairs would tend to diminish, falling to zero in the $4 \times$ simulation period. The proportions of positively significant $I$ s and SNDs also decreased to zero in the simulation. The reason for the weakening of the genetic clustering to more than the level of the KU would be attributed to no regeneration in our simulation. The correlogram of NAC indicated that the genetic clustering would still exist after seven simulation periods. As the NAC is based on multiple loci, it can detect the cumulative effect of faint genetic clustering in individual loci. Therefore, 
the NAC would detect the underlying genetic structure more sensitively than Moran's $I$ and SND. The grand mean of NAC decreased from 1.684 to 1.665 in the simulation but it remained significantly higher than the NAC of KU (1.649), indicating less genetic variability and higher genetic similarity of the AK. Even though the genetic clustering of two-locus genotypes at three linkage-disequilibrium-retained locus pairs was completely eliminated during the simulation, linkage disequilibria still remained. The disequilibrium at a given locus would usually be resolved in a single generation of random mating; however, linkage disequilibrium of combined genotype frequencies between two given loci caused by founder effects is retained over several generations (Hartl \& Clark, 1997).

\section{Implications for genetic conservation and management}

It is clear that forest cutting slightly but significantly decreased the genetic variability and reinforced the genetic structure in AK by reducing the mixing of half-sib progenies derived from a limited number of reproductive trees. The changed genetic structure, however, is probably only a temporary effect, as the changes would be almost eliminated during the self-thinning process, according to our simulation. However, linkage disequilibrium and the reduced genetic variability were not eliminated in the selfthinning process simulation. These results suggest that the reduced genetic variability and linkage disequilibrium would have a significant influence over several generations. Reductions in variability imply a higher potential for inbreeding depression, and the existence of linkage disequilibrium means distortions in the composition of the gene set in the population. If the natural composition of the gene set is assumed to be the most highly adapted to a given environment, linkage disequilibrium also implies reductions in the adaptability of populations in succeeding generations, which could be detrimental to conservation of important genetic resources.

\section{Acknowledgements}

We especially thank Drs Akihide Takehara, Masatoshi Hara and Yoshihiko Hirabuki for providing us access to their survey field at the foot of Mt. Kurikoma. We would like to express our appreciation to Mamoru Ueta for his help in mapping, and to Chidzuru Murakami, Rika Chiba, and Setsuko Chiba for their technical assistance. Without their vigorous help, it would have been impossible to complete this study. We thank Drs Tomiyasu Miyaura, Nobuhiro Tomaru and Yoshihiko Tsumura for their helpful advice. Finally, we are grateful to two anonymous reviewers of this study for their acute recommendations. We believe that this study has been much improved by their advice.

\section{References}

BERG, E. E. AND HAMRICK, J. L. 1995. Fine-scale genetic structure of a turkey oak forest. Evolution, 49, 110-120.

DEGEN, B., GREGORIUS, H.-R. AND SCHOLZ, F. 1996. ECO-GENE, a model for simulation studies on the spatial and temporal dynamics of genetic structures of tree populations. Silvae Genet., 45, 323-329.

DEMESURE, B., COMPS, B. AND PETIT, R. J. 1996. Chloroplast DNA phylogeography of the common beech (Fagus sylvatica) in Europe. Evolution, 50, 2515-2520.

EPPERSON, B. K. AND ALLARD, R. W. 1989. Spatial autocorrelation analysis of the distribution of genotypes within populations of lodgepole pine. Genetics, 121, 369-378.

GEBREK, T. AND KNOWLES, P. 1994. Genetic architecture in bur oak, Quercus macrocarpa (Fagaceae), inferred by means of spatial autocorrelation analysis. Pl. Syst. Evol., 189, $63-74$.

HAMRICK, J. L., GODT, M. J. W. AND SHERMAN-BROYLES, S. L. 1992. Factors influencing levels of genetic diversity in woody plant species. New Forests, 6, 95-124.

HAMRICK, J. L., MURAWSKI, D. A., NASON, J. D. 1993. The influence of seed dispersal mechanisms on the genetic structure of tropical tree populations. Vegetatio, 107/108, 281-297.

HARTL, D. L. AND Clark, A. G. 1997. Principles of Population Genetics. Sinauer Associates, Sunderland, MA.

KAWANO, S. AND KITAMURA, K. 1997. Demographic genetics of the Japanese beech, Fagus crenata, in the Ogawa forest preserve, Ibaraki, central Honshu, Japan. III. Population dynamics and genetic substructuring within a metapopulation. Pl. Sp. Biol., 12, 157-177.

KIMURA, M. AND CROW, J. F. 1964. The number of alleles that can be maintained in a finite population. Genetics, 49 , 725-738.

KNOWLES, P. 1991. Spatial genetic structure within two natural stands of black spruce (Picea mariana (Mill.) B.S.P.). Silvae Genet., 40, 13-19.

KNOWLES, P., PERRY, D. J. AND FOSTER, H. A. 1992. Spatial genetic structure in two tamarack [Larix laricina (Du Roi) K. Koch] populations with differing establishment histories. Evolution, 46, 572-576.

LEONARDI, S. AND MENOZZI, P. 1996. Spatial structure of genetic variability in natural stands of Fagus sylvatica L. (beech) in Italy. Heredity, 77, 359-368.

LEWIS, P.O. AND ZAYKIN, D. 1999. Genetic data analysis: computer program for the analysis of allelic data. Version $1.0(\mathrm{~d} 12)$. Free program distributed by the authors over the internet from the GDA Home Page at http://chee.unm.edu/gda/

MAEDA, T. 1988. Studies on natural regeneration of beech (Fagus crenata Blume). Special Bull. College Agriculture, Utsunomiya University, 46, 1-79 (in Japanese).

MERZEAU, D., COMPS, B., THIEBAUT, B., CUGUEN, J. AND LETOUZEY, J. 1994. Genetic structure of natural stands of Fagus sylvatica L. (beech). Heredity, 72, 269-277. 
NEI, M. 1987. Molecular Evolutionary Genetics. Columbia University Press, New York.

ŠIDÁK, Z. 1967. Confidence regions for the means of multivariate normal distributions. J. Am. Stat. Ass., 62, 626-633.

SOKAL, R. R. AND JACQUEZ, G. M. 1991. Testing inferences about microevolutionary processes by means of spatial autocorrelation analysis. Evolution, 45, 152-168.

SOKAL, R. R. AND ODEN, D. L. 1978a. Spatial autocorrelation in biology. 1. Methodology. Biol. J. Linn. Soc., 10, 199-228.

SOKAL, R. R. AND ODEN, D. L. 1978b. Spatial autocorrelation in biology. 2. Some biological implications and four applications of evolutionary and ecological interest. Biol. J. Linn. Soc., 10, 229-249.

SOKAL, R. R. AND WARTENBERG, D. E. 1983. A test of spatial autocorrelation analysis using an isolation-by-distance model. Genetics, 105, 219-237.

SOKAL, R. R., ODEN, D. L. AND THOMSON, B. A. 1997. A simulation study of microevolutionary inferences by spatial autocorrelation analysis. Biol. J. Linn. Soc., 60, 73-93.

SURLES, S. E., ARNOLD, J., SCHNABEL, A., HAMRICK, J. L. AND BONGARTEN, B. C. 1990. Genetic relatedness in open-pollinated families of two leguminous tree species, Robinia pseudoacacia L. and Gleditsia triacanthos L. Theor. Appl. Genet., 80, 49-56.

TOMARU, N., MITSUTSUJI, T., TAKAhASHI, M., TSUMURA, Y., UCHIDA, K. AND OHBA, K. 1997. Genetic diversity in Fagus crenata (Japanese beech): influence of the distributional shift during the last-Quaternary. Heredity, 78, 241-251.

TOMARU, N., TAKAHASHI, M., TSUMURA, Y., TAKAHASHI, M. AND OHBA, K. 1998. Intraspecific variation and phylogeographic patterns of Fagus crenata (FAGACEAE) mitochondrial DNA. Am. J. Bot., 85, 629-636.

TROGGIO, M., DiMASSO, E., LEONARDI, S., CERONI, M., BUCCI, G., PIOVANI, P. AND MENOZZI, P. 1996. Inheritance of RAPD and I-SSR markers and population parameters estimation in European beech (Fagus crenata L.). For. Genet., 3, 173-181.

TSUMURA, Y., TOMARU, N., SUYAMA, Y., NAİEIM, M. AND OHBA, K. 1990. Laboratory manual of isozyme analysis. Bull. Tsukuba University For., 6, 63-95 (in Japanese).

XIE, C. Y. AND KNOWLES, P. 1991. Spatial genetic substructure within natural populations of jack pine (Pinus banksiana). Can. J. Bot., 69, 547-551.

YANAGIYA, S., KON, T. AND KONISHI, A. 1969. The results of natural regeneration with bush clearing by remaining tree management system in Buna (Fagus crenata) forest. Ann. Report Tohoku Branch, For. Expt. Sta., 10, 124-135 (in Japanese).

YOUNG, A. G. AND MERRIAM, H. G. 1994. Effects of forest fragmentation on the spatial genetic structure of Acer saccharum Marsh. (sugar maple) populations. Heredity, $\mathbf{7 2}$, 201-208. 